\title{
Genetic variation of carotenoids in Chinese bread wheat cultivars and the effect of the 1BL.1RS translocation
}

\author{
Wenshuang LI ${ }^{1}$, Shengnan ZHAI ${ }^{1}$, Hui JIN ${ }^{1}$, Weie WEN ${ }^{1,2}$, Jindong LIU ${ }^{1}$, Xianchun XIA ${ }^{1}$, Zhonghu HE (凶) $)^{1,3}$ \\ 1 Institute of Crop Science/National Wheat Improvement Center, Chinese Academy of Agricultural Sciences (CAAS), Beijing 100081, China \\ 2 College of Agronomy, Xinjiang Agricultural University, Urumqi 830052, China \\ 3 International Maize and Wheat Improvement Center (CIMMYT) China Office, c/o CAAS, Beijing 100081, China
}

\begin{abstract}
Carotenoid content of wheat is an important criterion for prediction of the commercial and nutritional value of products made from bread wheat (Triticum aestivum) cultivars. The objective of this study was to determine the major components of carotenoids in Chinese wheat using ultra performance liquid chromatography (UPLC) including lutein, zeaxanthin, $\alpha$-carotene and $\beta$-carotene. Grain carotenoid content was investigated in 217 cultivars from three major Chinese wheat regions and from seven other countries grown in two environments. Genotype contributed to the majority of variation in carotenoid components. Lutein, zeaxanthin and $\beta$-carotene concentrations varied from 18.3 to $100.1,4.9$ to 12.0 and 0.9 to $48.7 \mu \mathrm{g}$ per $100 \mathrm{~g}$ in wheat flour with an average of $40.2,7.2$ and $18.2 \mu \mathrm{g}$ per $100 \mathrm{~g}$, respectively. Lutein (61.3\%) was the main carotenoid component, followed by $\beta$-carotene $(27.7 \%)$ and zeaxanthin $(11.0 \%)$. No $\alpha$-carotene was detected. Total carotenoids, lutein, zeaxanthin and $\beta$-carotene were all higher in cultivars with the 1BL.1RS translocation compared to those without the translocation. This is the first report on assay of lutein, zeaxanthin and $\beta$-carotene concentrations for a large number of wheat cultivars. These data will be useful for genetic improvement of wheat carotenoid content and for understanding of the carotenoid biosynthetic pathway in wheat.
\end{abstract}

Keywords Triticum aestivum, carotenoids, nutritional quality, UPLC

\section{Introduction}

Bread wheat (Triticum aestivum) is one of the most important crops in the world with China being the largest

Received February 22, 2016; accepted March 21, 2016

Correspondence: zhhecaas@163.com wheat producer and consumer, with about 24 million $\mathrm{hm}^{2}$ sown and about $110 \mathrm{Mt}$ harvested. Given its importance in human diets, it would be of great benefit to increase carotenoid concentrations of wheat grain.

Carotenoids are a diverse group of lipid-soluble organic pigments synthesized in fruits, vegetables and cereal grains that impart yellow/orange color to agricultural products ${ }^{[1]}$. More than 700 carotenoids have been described and divided into two classes, carotenes and xanthophylls, which are hydrocarbons and oxygenated derivatives, respectively ${ }^{[2]}$. Carotenoids perform important functions in plants, such as harvesting light for photosynthesis and protecting chlorophyll against oxidative damage ${ }^{[3]}$. Animals and humans are unable t1o synthesize carotenoids and must obtain them from their diet ${ }^{[4]}$. Carotenoids have several functions in improving human health and nutrition. Epidemiological studies have indicated associations between carotenoid-rich diets and reduced risk of chronic diseases such as cancer ${ }^{[5]}$, cardiovascular disease ${ }^{[6]}$ and amyotrophic lateral sclerosis ${ }^{[7]}$. Carotenoids, mainly lutein and zeaxanthin, are also crucial for prevention of frequently-occurring eye diseases, such as age-related macular degeneration, cataracts, and retinitis pigmentosa ${ }^{[8]}$. $\beta$-carotene is vitamin A precursor, which can reduce childhood mortality or growth retardation. In addition to their nutritional and health values, carotenoids are important components of yellow pigment content (YPC) in bread wheat grain and flour. YPC influences the color of the end products, which is an important quality criterion for the noodle and steamed bread industry. Several studies of carotenoids content in wheat or wheat relatives have been reported ${ }^{[1,9,10]}$. Adom et al. ${ }^{[11]}$ found that lutein was the most abundant carotenoid in 11 wheat cultivars. Carotenoids had a wide range of concentrations and differed significantly between wheat cultivars. Okarter et al. ${ }^{[12]}$ concluded that lutein and zeaxanthin concentrations were higher in eight diverse wheat cultivars than 
reported for previous studies. Einkorn wheat was reported to exhibit the highest concentration of lutein, followed by durum, while bread wheat had the lowest concentration ${ }^{[1]}$. Studies of carotenoid content have mainly included durum and einkorn wheat ${ }^{[13]}$, with much less data being reported for bread wheat cultivars. Knowledge of carotenoid content of wheat is important for the food industry and therefore breeding programs to develop new cultivars and products with enhanced nutritional and quality properties $^{[14]}$.

The 1BL.1RS translocation is used in wheat breeding and is present in about $45 \%$ of Chinese wheat cultivars and advanced lines ${ }^{[15]}$. Studies of the effects of the 1BL.1RS translocation in bread wheat have concentrated on resistance to rust and powdery mildew, yield potential, and a detrimental effect on gluten strength, bread and noodle quality ${ }^{[16,17]}$. The effects of the 1BL.1RS translocation on flour color and YPC in bread wheat were reported in an earlier study ${ }^{[18]}$. However, the effects of the 1BL.1RS translocation on carotenoids components contents in wheat have not been assessed.

An ultra-performance liquid chromatography (UPLC) system offers higher sensitivity, faster analysis and better resolution than high performance liquid chromatography (HPLC), and was first developed by the Waters Corporation. Separation in UPLC is performed under very high pressure, and separation efficiency is significantly improved over HPLC ${ }^{[19]}$. Thus, the objective of the present study was to determine the variation in carotenoid content (including composition and concentrations) among 217 bread wheat cultivars using the UPLC system.

\section{Materials and methods}

\subsection{Materials}

\subsubsection{Plant material}

Grain samples from three trials grown during the 20122013 cropping season, including 217 cultivars, were used to determine the contents and components of carotenoids (Appendix A, Tables S1-S3). In Trial 1, 39 wheat cultivars, including 36 from the northern winter wheat region (Region 1) of China and three from the U.S.A, were planted in Beijing and Shijiazhuang, Hebei. In Trial 2, 119 Chinese cultivars from the Yellow and Huai River valleys facultative wheat region (Region 2) and 19 cultivars from five different countries were grown in Anyang, Henan, and Suixi, Anhui. In Trial 3, 40 Chinese cultivars from the middle and lower Yangtze River autumn-sown spring wheat region (Region 3) were grown at Suixi, Anhui, and Chengdu, Sichuan. All genotypes were planted in randomized complete blocks with two replicates at each location, and each accession was planted in a single $1.5 \mathrm{~m}$ row of 50 seeds with $25 \mathrm{~cm}$ between rows. All harvested samples were sound and showed no evidence of preharvest sprouting.

The 1BL.1RS translocation had a significant effect on yellow pigment content in a previous study; therefore the presence of the 1BL.1RS translocation was determined using molecular markers ${ }^{[18]}$. There were 9,65 and 9 cultivars with the 1BL.1RS translocation in Region 1, Region 2, and Region 3 groups, respectively.

\subsubsection{Chemicals used}

Acetone and n-hexane were of analytical grade purchased from Beijing Chemical Factory. Butylated hydroxytoluene (BHT) and standards for lutein (90\% purity), zeaxanthin (95\% purity) and $\beta$-carotene (95\% purity) were purchased from Sigma-Aldrich Co. LLC (St. Louis, Missouri, USA). $\alpha$-Carotene standard was purchased from CaroteNature $\mathrm{GmbH}$ (Ostermundigen, Switzerland). Solvents used for UPLC, methanol, acetonitrile, ethyl acetate, dichloromethane, and triethylamine, were purchased from SigmaAldrich, and all solvents used were HPLC grade.

\subsection{Methods}

\subsubsection{Sample preparation for carotenoids determination}

After harvest, hard, medium hard and soft wheat samples were tempered to around $16.5 \%, 15.5 \%$ and $14.5 \%$ moisture contents, respectively, for $16 \mathrm{~h}$ and milled into flour using a Brabender Quandrumat Junior mill (Brabender GmbH \& Co. KG, Duisburg, Germany). The milled samples were passed through a 60 -mesh sieve using a rotary box for $5 \mathrm{~min}$, and then reduced into flour by a gradual reduction system. To minimize the degradation of pigments by oxidative enzymes and light, flour samples were stored at $18^{\circ} \mathrm{C}$ in a room with dim light before analysis.

Carotenoids from the flour were extracted following the method of Ramachandran et al. ${ }^{[20]}$, with the following modifications. Accurately-measured $8.0 \mathrm{~g}$ flour samples were transferred to $100 \mathrm{~mL}$ bottles with glass stoppers and extracted with $40 \mathrm{~mL}$ of solvent (n-hexane/acetone, 8:2, $\mathrm{v} / \mathrm{v}, 0.1 \%$ BHT w/v). Samples were mixed on a vortex mixer for $1-2$ min and shaken at $300 \mathrm{r} \cdot \mathrm{min}^{-1}$ on a constant temperature gyratory shaker for $1 \mathrm{~h}$ at $35^{\circ} \mathrm{C}$. Mixtures were moved to a $50 \mathrm{~mL}$ centrifuge tube and centrifuged at $13500 \mathrm{r} \cdot \mathrm{min}^{-1}$ for $15 \mathrm{~min}$ at $4^{\circ} \mathrm{C}$. Supernatants were retained, transferred to $100 \mathrm{~mL}$ beakers and evaporated to dryness at $35^{\circ} \mathrm{C}$ under a nitrogen stream using a nitrogen evaporator system. Dry residues containing carotenoids were re-dissolved in $1.5 \mathrm{~mL}$ of methanol/ethyl acetate $(68: 32, \mathrm{v} / \mathrm{v})$ with $0.1 \%$ BHT. The organic layers were transferred to a $2 \mathrm{~mL}$ micro-centrifuge tubes at $-20^{\circ} \mathrm{C}$ before analysis. They were centrifuged at $12000 \mathrm{r} \cdot \mathrm{min}^{-1}$ for $20 \mathrm{~min}$ at $4^{\circ} \mathrm{C}$. Supernatants were filtered through $0.22 \mu \mathrm{m}$ polyvinylidene fluoride syringe filters into $2 \mathrm{~mL}$ 
brown micro-centrifuge tubes and $200 \mu \mathrm{L}$ samples were transferred into glass vials with screw caps for automatic sampling, using $8 \mu \mathrm{L}$ for UPLC analysis. All procedures were carried out under dim light, and extracts were placed in brown tubes to avoid sample degradation by photooxidation.

\subsubsection{Standards preparation}

Pure standards of lutein, zeaxanthin, $\alpha$-carotene, and $\beta$-carotene were first dissolved in dichloromethane and then diluted in methanol, to obtain $0.1 \mathrm{mg} \cdot \mathrm{mL}^{-1}$ of lutein, zeaxanthin, $\alpha$-carotene, and $0.05 \mathrm{mg} \cdot \mathrm{mL}^{-1}$ of $\beta$-carotene standard solutions, then stored in darkness at $-20^{\circ} \mathrm{C}$. Each standard solution was diluted in methanol/ethyl acetate $(68: 32, \mathrm{v} / \mathrm{v})$ and injected alone, for detection of their retention times at $450 \mathrm{~nm}$. Then, five-point calibration curves were built from a mix of all standard solutions.

\subsubsection{UPLC analysis}

UPLC was run on a Waters Acquity system (Waters Corporation, Milford, MA, USA), equipped with a photodiode array detector at $450 \mathrm{~nm}$. Millennium 32 software from Waters was used for instrument control, data acquisition and data processing. A YMC Carotenoid Reverse Phase Column $(4.6 \mathrm{~mm} \times 100 \mathrm{~mm}$ i.d., $3 \mu \mathrm{m}$ particle size) was used with gradients of acetonitrile/ methanol/water/triethylamine $(81: 14: 5: 0.05, \mathrm{v} / \mathrm{v} / \mathrm{v} / \mathrm{v})$ (A) and methanol/ethyl acetate/triethylamine $(68: 32: 0.05$, $\mathrm{v} / \mathrm{v} / \mathrm{v}$ ) (B). The mobile phase was first degassed by sonication for $20 \mathrm{~min}$. The gradient was programmed as follows: (1) initial conditions of $100 \%$ solution $\mathrm{A}$; (2) a 0.3 min linear gradient with $100 \%$ solution $A$; (3) a 11.7 min linear gradient with solution A from $100 \%$ to $0 \%$ and solution B from $0 \%$ to $100 \%$; (4) a 8 min linear gradient with $100 \%$ solvent $\mathrm{B}$; (5) a 2 min linear gradient with solution A from $0 \%$ to $100 \%$ and solution B from $100 \%$ to $0 \%$; (6) a 3 min linear gradient with $100 \%$ solvent A. Flow rate was $0.4 \mathrm{~mL} \cdot \mathrm{min}^{-1}$. Column temperature was maintained at $35^{\circ} \mathrm{C}$. Eight microliters of samples were injected for UPLC analysis.

Carotenoids were detected at $450 \mathrm{~nm}$ and identified by comparison of retention times and spectral analyses for pure standard solutions. The sample chamber was maintained at $15^{\circ} \mathrm{C}$ and samples were injected within $24 \mathrm{~h}$ after extraction.

\subsubsection{Molecular detection of the 1BL.1RS translocation}

Genomic DNA was extracted from three kernels of each cultivar using a method modified from Lagudah et al. ${ }^{[21]}$. A marker H20 was employed to detect 1BL.1RS translocations $^{[22]}$. PCR was performed in volumes of $20 \mu \mathrm{L}$, including $10 \mu \mathrm{L} 2 \times$ GC buffer I, $100 \mu \mathrm{mol}$ of each dNTP,
2 pmol of each primer, $1 \mathrm{U}$ of ExTaq, and $80 \mathrm{ng}$ of template DNA. All reagents were from Takara Biotechnology Co., Ltd. (http://www.takara.com.cn). The PCR program was: denaturing at $94^{\circ} \mathrm{C}$ for $5 \mathrm{~min}$, followed by 35 cycles of denaturing at $94^{\circ} \mathrm{C}$ for $1 \mathrm{~min}$, annealing at $52-60^{\circ} \mathrm{C}$ for $1 \mathrm{~min}, 72^{\circ} \mathrm{C}$ for $2 \mathrm{~min}$, and a final extension at $72^{\circ} \mathrm{C}$ for $5 \mathrm{~min}$. PCR products were separated by electrophoresis in $1 \%$ agarose gels stained with ethidium bromide and visualized using UV light.

\subsubsection{Statistical analysis}

The data are reported as mean $\pm \mathrm{SD}$ (standard deviation) for UPLC assay. Analysis of variance (ANOVA) was performed with the SAS/STAT software version 9.1 (SAS Institute Inc., Cary, NC, USA). PROC GLM was used in ANOVA, where genotypes were considered as fixed effects, whereas environments and replications nested in environment were considered as random effects. The effects of genotype $(\mathrm{G})$, environment $(\mathrm{E})$, and their interaction $(\mathrm{G} \times \mathrm{E})$ on carotenoid content were evaluated for the 217 wheat cultivars. $t$-tests between cultivars with and without 1BL.1RS translocation were analyzed using SAS 9.1.

\section{Results and discussion}

\subsection{Effects of genotype, environment and their interactions}

The concentrations of carotenoid components, viz. lutein, zeaxanthin and $\beta$-carotene, were determined in 217 bread wheat cultivars from Trials 1,2 , and 3. No $\alpha$-carotene was found in any of the samples. ANOVA was conducted for lutein, zeaxanthin, and $\beta$-carotene data across two environments. The significant variation in concentrations of carotenoid components was attributed to $\mathrm{G}, \mathrm{E}, \mathrm{G} \times \mathrm{E}$ interaction in the three trials (Table 1). In Region $1, \mathrm{G}$ contributed to the majority of variation in lutein, zeaxanthin and $\beta$-carotene $(P<0.01)$. E made a significant contribution to lutein and $\beta$-carotene $(P<0.01) . \mathrm{G} \times \mathrm{E}$ interaction made a significant contribution to zeaxanthin $(P<0.05)$ and $\beta$-carotene $(P<0.01)$. The ANOVA indicated significant $\mathrm{G}, \mathrm{E}$ and $\mathrm{G} \times \mathrm{E}$ interaction differences $(P<0.01)$ among 138 Region 2 bread wheat samples for carotenoid components. In Region 3, the effects of $\mathrm{G}$ and $\mathrm{E}$ were significant for variation in lutein, zeaxanthin and $\beta$-carotene $(P<0.01) . \mathrm{G} \times \mathrm{E}$ interaction contributed to a big variation $(P<0.01)$ in lutein and $\beta$-carotene.

The large differences in carotenoid components reported previously may be attributed to different extraction methods, milling fractions, particle size and HPLC procedures $^{[2,9,14]}$. Several studies have shown that genetic effects and environmental conditions may significantly 
Table 1 Analysis of variance of the concentration of carotenoid components for three sets of bread wheat cultivars across two environments. Data are the $F$ value

\begin{tabular}{|c|c|c|c|c|c|c|}
\hline \multirow{2}{*}{ Source of variance } & \multicolumn{2}{|c|}{ Region 1} & \multicolumn{2}{|c|}{ Region 2} & \multicolumn{2}{|c|}{ Region 3} \\
\hline & $d f$ & $F$ value & $d f$ & $F$ value & $d f$ & $F$ value \\
\hline \multicolumn{7}{|l|}{ Lutein } \\
\hline Genotypes & 38 & $26.08^{* *}$ & 137 & $24.60^{* *}$ & 39 & $61.53^{* *}$ \\
\hline Environments & 1 & $41.44^{* *}$ & 1 & $274.23^{* *}$ & 1 & $1242.99^{* *}$ \\
\hline Replications (Environments) & 2 & 2.27 & 2 & 1.98 & 2 & $9.87^{* *}$ \\
\hline Genotypes $\times$ Environments & 38 & 1.42 & 137 & $2.20^{* *}$ & 39 & $3.58^{* *}$ \\
\hline \multicolumn{7}{|l|}{ Zeaxanthin } \\
\hline Genotypes & 38 & $3.27^{* *}$ & 137 & $5.85^{* *}$ & 39 & $15.69^{* *}$ \\
\hline Environments & 1 & 0.09 & 1 & $267.84^{* *}$ & 1 & $527.21^{* *}$ \\
\hline Replications (Environments) & 2 & 0.45 & 2 & $19.88^{* *}$ & 2 & 2.86 \\
\hline Genotypes $\times$ Environments & 38 & $1.74^{*}$ & 137 & $1.64^{* *}$ & 39 & 1.21 \\
\hline \multicolumn{7}{|l|}{$\beta$-carotene } \\
\hline Genotypes & 38 & $33.15^{* *}$ & 137 & $23.30^{* *}$ & 39 & $103.73^{* *}$ \\
\hline Environments & 1 & $8.65^{* *}$ & 1 & $330.97^{* *}$ & 1 & $71.74^{* *}$ \\
\hline Replications (Environments) & 2 & $8.60^{* *}$ & 2 & $5.82^{* *}$ & 2 & $7.04^{* *}$ \\
\hline Genotypes $\times$ Environments & 38 & $2.54^{* *}$ & 137 & $2.80^{* *}$ & 39 & $3.10^{* *}$ \\
\hline
\end{tabular}

Note: *, $P<0.05$;**, $P<0.01$. Region 1, Northern winter wheat region; Region 2, Yellow and Huai River valleys facultative wheat region; Region 3, middle and lower Yangtze River autumn-sown spring wheat region.

affect carotenoid content of wheat ${ }^{[1,23]}$. Three einkorn accessions selected for a high concentration of lutein and a bread wheat cultivar grown in four environments were used to investigate the influence of location on the lutein content $^{[1]}$. The lutein concentration showed significant differences among wheat accessions and at four locations. The effects of $G, E$ and $G \times E$ on carotenoids were also investigated using flour samples of 10 soft winter wheat cultivars grown at four different locations ${ }^{[23]}$. The largest variation in lutein, zeaxanthin and total carotenoids were attributed to $\mathrm{E}$, followed by $\mathrm{G} \times \mathrm{E}$ interaction and then $\mathrm{G}$. Limited data have been published on the effects of genetic and environmental conditions for a large number of bread wheat cultivars. ANOVA from three trials in the present study demonstrated that $\mathrm{G}$ contributed to the greatest variation in carotenoid content, which was probably a consequence of the large number of cultivars assessed.

\subsection{Carotenoids components}

A wide range of variation for concentrations of all carotenoid components was observed in Chinese wheat. Lutein and zeaxanthin were detected in all samples. The lutein concentration varied from 18.3 to $100 \mu \mathrm{g}$ per $100 \mathrm{~g}$, with a mean of $40.2 \mu \mathrm{g}$ per $100 \mathrm{~g}$, and was the primary carotenoid in extracts. This finding is in agreement with the previous reports for diploid, tetraploid and bread wheat ${ }^{[3,9,11,13]}$ where lutein accounted for a mean of about $90 \%$ of the total carotenoids in einkorn wheat and $70 \%-80 \%$ for bread wheat ${ }^{[3,24]}$.

Zeaxanthin concentration varied from 4.88 to $12.0 \mu \mathrm{g}$ per $100 \mathrm{~g}$, with a mean of $7.21 \mu \mathrm{g}$ per $100 \mathrm{~g}$. Lutein and zeaxanthin concentrations in the present study were a little lower than previously reported for 11 wheat cultivars ${ }^{[11]}$. The difference may be attributed to the extraction and analytical conditions, genetic effects, different growing environments, and/or their interactions.

The concentration of $\beta$-carotene varied from 0.89 to $48.7 \mu \mathrm{g}$ per $100 \mathrm{~g}$, with a mean of $18.2 \mu \mathrm{g}$ per $100 \mathrm{~g}$. This was higher than reported for durum wheat and ein$\operatorname{korn}^{[9,14,25]}$. Most samples had $\beta$-carotene, but it was absent from nine cultivars (Chuanmai 42, Chuanmai 43, Chuannong 23, Emai 11, En 5, Fan 6, Jingmai 103, Yangmai 158, and Yangmai 10) probably because their $\beta$-carotene concentrations were too low to be detected by the UPLC system.

In this work, lutein accounted for $61.3 \%$ of three carotenoids components followed by $\beta$-carotene and zeaxanthin, sharing $27.7 \%$ and $11.0 \%$, respectively. Of the total carotenoids (lutein + zeaxanthin $+\beta$-carotene) concentrations, the average proportion of $\beta$-carotene in bread wheat measured in this study was higher than those of durum wheat and einkorn ${ }^{[9,14,25]}$. In some bread wheat samples, the lutein concentration was higher than the others, whereas their $\beta$-carotene concentration was lower. The high accumulation of lutein and the relatively low levels of $\beta$-carotene could indicate dominance of the carotenoids biosynthetic pathway in producing the lutein. This is consistent with the findings of Humphries et al. ${ }^{[26]}$, who reported high lutein concentrations as well as relatively low $\beta$-carotene concentrations. In addition, the lutein concentration was higher in durum than wild 
tetraploid wheat; however, $\beta$-carotene concentration was lower in durum ${ }^{[14]}$. Bread wheat had a higher percentage of $\beta$-carotene and lower lutein concentration than durum. No $\alpha$-carotene was found in the bread wheat cultivars. Moore et al. ${ }^{[25]}$ also reported that lutein was the primary carotenoid present in eight wheat cultivars, along with significant amounts of zeaxanthin and $\beta$-carotene.

3.3 Variation between cultivars with and without 1BL.1RS translocation

In Region 1, there were no significant differences in total carotenoids (lutein + zeaxanthin $+\beta$-carotene), lutein, and $\beta$-carotene concentration between cultivars with and without 1BL.1RS translocation $(P<0.05$, Table 2$)$. However, total carotenoids, lutein, zeaxanthin, and $\beta$-carotene concentrations in cultivars with 1BL.1RS translocation were significantly higher than those without the translocation in Region $2(P<0.05$, Table 3). For Region 3, the contents of total carotenoids and $\beta$-carotene were also significantly higher in cultivars with 1BL.1RS translocation than those without the translocation $(P<0.05$, Table 4). Notably, a major quantitative trait locus for YPC was identified on chromosome

Table 2 Comparison of carotenoid content of bread wheat cultivars with and without 1BL.1RS translocation in the northern winter wheat region

\begin{tabular}{|c|c|c|c|c|c|}
\hline Component & Genotype & Number of accessions & Mean $(\mu \mathrm{g}$ per $100 \mathrm{~g})$ & $S D$ & Range ( $\mu \mathrm{g}$ per $100 \mathrm{~g})$ \\
\hline \multirow{2}{*}{$\begin{array}{l}\text { Total carotenoids (Lutein }+ \text { zeaxanthin }+ \\
\beta \text {-carotene) }\end{array}$} & 1BL.1RS & 9 & $78.5^{\mathrm{a}}$ & 12.34 & $63.3-97.7$ \\
\hline & Non-1BL.1RS & 30 & $69.5^{\mathrm{a}}$ & 13.90 & $46.2-106.6$ \\
\hline \multirow[t]{2}{*}{ Lutein } & 1BL.1RS & 9 & $48.4^{\mathrm{a}}$ & 7.01 & $39.3-56.8$ \\
\hline & Non-1BL.1RS & 30 & $41.7^{\mathrm{a}}$ & 9.42 & $24.6-62.1$ \\
\hline \multirow[t]{2}{*}{ Zeaxanthin } & 1BL.1RS & 9 & $7.0^{\mathrm{a}}$ & 0.29 & $6.5-7.6$ \\
\hline & Non-1BL.1RS & 30 & $6.7^{\mathrm{b}}$ & 0.61 & $5.3-7.6$ \\
\hline \multirow[t]{2}{*}{$\beta$-carotene } & 1BL.1RS & 9 & $23.0^{\mathrm{a}}$ & 12.12 & $2.0-37.9$ \\
\hline & Non-1BL.1RS & 30 & $21.1^{\mathrm{a}}$ & 7.47 & $3.4-36.9$ \\
\hline
\end{tabular}

Note: Values with different letters in each column are significantly different at $P<0.05$.

Table 3 Comparison of carotenoid content of bread wheat cultivars with and without 1BL.1RS translocation in the Yellow and Huai River valleys facultative wheat region

\begin{tabular}{|c|c|c|c|c|c|}
\hline Component & Genotype & Number of accessions & Mean $(\mu \mathrm{g}$ per $100 \mathrm{~g})$ & $S D$ & Range $(\mu \mathrm{g}$ per $100 \mathrm{~g})$ \\
\hline \multirow{2}{*}{$\begin{array}{l}\text { Total carotenoids (Lutein }+ \text { zeaxanthin }+ \\
\beta \text {-carotene) }\end{array}$} & 1BL.1RS & 65 & $76.1^{\mathrm{a}}$ & 17.85 & $42.2-121.7$ \\
\hline & Non-1BL.1RS & 73 & $61.3^{\mathrm{b}}$ & 13.90 & $39.6-115.9$ \\
\hline \multirow[t]{2}{*}{ Lutein } & 1BL.1RS & 65 & $46.2^{\mathrm{a}}$ & 14.96 & $26.2-100.1$ \\
\hline & Non-1BL.1RS & 73 & $39.7^{\mathrm{b}}$ & 10.73 & $23.5-93.9$ \\
\hline \multirow[t]{2}{*}{ Zeaxanthin } & 1BL.1RS & 65 & $8.1^{\mathrm{a}}$ & 1.25 & $5.8-11.9$ \\
\hline & Non-1BL.1RS & 73 & $7.4^{\mathrm{b}}$ & 0.94 & $5.4-12.0$ \\
\hline \multirow[t]{2}{*}{$\beta$-carotene } & 1BL.1RS & 65 & $21.9^{\mathrm{a}}$ & 11.74 & $4.0-48.7$ \\
\hline & Non-1BL.1RS & 73 & $14.3^{\mathrm{b}}$ & 6.45 & $3.3-32.4$ \\
\hline
\end{tabular}

Note: Values with different letters in each column are significantly different at $P<0.05$.

Table 4 Comparison of carotenoid content of bread wheat cultivars with and without 1BL.1RS translocation in the middle and lower Yangtze River autumn-sown spring wheat region

\begin{tabular}{|c|c|c|c|c|c|}
\hline Component & Genotype & Number of accessions & Mean $(\mu \mathrm{g}$ per $100 \mathrm{~g})$ & $S D$ & Range ( $\mu \mathrm{g}$ per $100 \mathrm{~g})$ \\
\hline \multirow{2}{*}{$\begin{array}{l}\text { Total carotenoids (Lutein }+ \text { zeaxanthin }+ \\
\beta \text {-carotene) }\end{array}$} & 1BL.1RS & 9 & $59.4^{\mathrm{a}}$ & 13.20 & $46.0-82.5$ \\
\hline & Non-1BL.1RS & 31 & $48.2^{\mathrm{b}}$ & 9.34 & $34.9-73.8$ \\
\hline \multirow[t]{2}{*}{ Lutein } & 1BL.1RS & 9 & $30.1^{\mathrm{a}}$ & 13.92 & $20.3-64.5$ \\
\hline & Non-1BL.1RS & 31 & $28.2^{\mathrm{a}}$ & 7.14 & $18.3-51.8$ \\
\hline \multirow[t]{2}{*}{ Zeaxanthin } & 1BL.1RS & 9 & $6.2^{\mathrm{a}}$ & 1.40 & $5.1-9.1$ \\
\hline & Non-1BL.1RS & 31 & $5.9^{\mathrm{a}}$ & 1.04 & $4.9-8.1$ \\
\hline \multirow[t]{2}{*}{$\beta$-carotene } & 1BL.1RS & 9 & $23.1^{\mathrm{a}}$ & 10.80 & $0.0-39.4$ \\
\hline & Non-1BL.1RS & 31 & $14.1^{\mathrm{b}}$ & 11.35 & $0.0-36.6$ \\
\hline
\end{tabular}

Note: Values with different letters in each column are significantly different at $P<0.05$. 
1BL.1RS ${ }^{[18]}$, which provides further evidence that $1 \mathrm{RS}$ has favorable allele(s) for carotenoids and therefore yellow pigment content.

\section{Conclusions}

Significant variation in carotenoid content among 217 bread wheat cultivars was detected by UPLC. Cultivars with the 1BL.1RS translocation usually had higher carotenoid content than those without the translocation. It is possible to modify the contents of carotenoids through genetic improvement and study the related genes involved in the of carotenoids biosynthetic pathway in bread wheat.

Acknowledgements The authors are grateful to Prof. Robert McIntosh, University of Sydney, Dr Mingli Wang, USDA-ARS, and Dr Yuanfeng Hao for reviewing this manuscript. Prof. Guixing Ren and Ms Fang Liu, from CAAS, also gave us assistance in this study. This study was supported by the International Collaboration Projects from Ministry of Science and Technology (2013DFG30530, 2014DFG31690).

Supplementary materials The online version of this article at http://dx. doi.org/10.15302/J-FASE-2016094 contains supplementary materials (Appendix A).

Compliance with ethics guidelines Wenshuang Li, Shengnan Zhai, Hui Jin, Weie Wen, Jindong Liu, Xianchun Xia, and Zhonghu He declare that they have no conflict of interest or financial conflicts to disclose.

This article does not contain any studies with human or animal subjects performed by any of the authors.

\section{References}

1. Abdel-Aal S M, Young J C, Rabalski I, Hucl P, Fregeau-Reid J. Identification and quantification of seed carotenoids in selected wheat species. Journal of Agricultural and Food Chemistry, 2007, 55(3): 787-794

2. Burkhardt S, Böhm V. Development of a new method for the complete extraction of carotenoids from cereals with special reference to durum wheat (Triticum durum Desf.). Journal of Agricultural and Food Chemistry, 2007, 55(21): 8295-8301

3. Hidalgo A, Brandolini A, Pompei C, Piscozzi R. Carotenoids and tocols of einkorn wheat (Triticum monococcum ssp. monococcum L.). Journal of Cereal Science, 2006, 44(2): 182-193

4. Ravel C, Dardevet M, Leenhardt F, Bordes J, Joseph J L, Perretant M R, Exbrayat F, Poncet C, Balfourier F, Chanliaud E. Improving the yellow pigment content of bread wheat flour by selecting the three homoeologous copies of Psy1. Molecular Breeding, 2013, 31 (1): 87-99

5. Jung S, Wu K, Giovannucci E, Spiegelman D, Willett W C, SmithWarner S A. Carotenoid intake and risk of colorectal adenomas in a cohort of male health professionals. Cancer Causes \& Control, 2013, 24(4): 705-717

6. Osganian S K, Stampfer M J, Rimm E, Spiegelman D, Manson J E, Willett W C. Dietary carotenoids and risk of coronary artery disease in women. American Journal of Clinical Nutrition, 2003, 77(6):
$1390-1399$

7. Fitzgerald K C, O’Reilly É J, Fondell E, Falcone G J, McCullough M L, Park Y, Kolonel L N, Ascherio A. Intakes of vitamin C and carotenoids and risk of amyotrophic lateral sclerosis: pooled results from 5 cohort studies. Annals of Neurology, 2013, 73(2): 236-245

8. Fullmer L A, Shao A. The role of lutein in eye health and nutrition. Cereal Foods World, 2001, 46(9): 408-413

9. Fratianni A, Irano M, Panfili G, Acquistucci R. Estimation of color of durum wheat. Comparison of WSB, HPLC, and reflectance colorimeter measurements. Journal of Agricultural and Food Chemistry, 2005, 53(7): 2373-2378

10. Lachman J, Hejtmánková K, Kotíková Z. Tocols and carotenoids of einkorn, emmer and spring wheat varieties: selection for breeding and production. Journal of Cereal Science, 2013, 57(2): 207-214

11. Adom K K, Sorrells M E, Liu R H. Phytochemical profiles and antioxidant activity of wheat varieties. Journal of Agricultural and Food Chemistry, 2003, 51(26): 7825-7834

12. Okarter N, Liu C S, Sorrells M E, Liu R H. Phytochemical content and antioxidant activity of six diverse varieties of whole wheat. Food Chemistry, 2010, 119(1): 249-257

13. Van Hung P, Hatcher D W. Ultra-performance liquid chromatography (UPLC) quantification of carotenoids in durum wheat: influence of genotype and environment in relation to the colour of yellow alkaline noodles (YAN). Food Chemistry, 2011, 125(4): 1510-1516

14. Digesù $\mathrm{A}$, Platani $\mathrm{C}$, Cattivelli L, Mangini G, Blanco A. Genetic variability in yellow pigment components in cultivated and wild tetraploid wheats. Journal of Cereal Science, 2009, 50(2): 210-218

15. Liu L, He Z H, Yan J, Zhang Y, Xia X C, Pena R J. Allelic variation at the Glu-1 and Glu-3 loci, presence of the 1B.1R translocation, and their effects on mixographic properties in Chinese bread wheats. Euphytica, 2005, 142(3): 197-204

16. He Z H, Liu L, Xia X C, Liu J J, Pena R J. Composition of HMW and LMW glutenin subunits and their effects on dough properties, pan bread, and noodle quality of Chinese bread wheats. Cereal Chemistry, 2005, 82(4): 345-350

17. Schlegel R, Meinel A. A quantitative trait locus (QTL) on chromosome arm 1RS of rye and its effect on yield performance of hexaploid wheat. Cereal Research Communications, 1994, 22(1): $7-13$

18. Zhang Y L, Wu Y P, Xiao Y G, He Z H, Zhang Y, Yan J, Zhang Y, Xia X C, Ma C X. QTL mapping for flour and noodle colour components and yellow pigment content in common wheat. Euphytica, 2009, 165(3): 435-444

19. Nováková L, Matysová L, Solich P. Advantages of application of UPLC in pharmaceutical analysis. Talanta, 2006, 68(3): 908-918

20. Ramachandran A, Pozniak C J, Clarke J M, Singh A K. Carotenoid accumulation during grain development in durum wheat. Journal of Cereal Science, 2010, 52(1): 30-38

21. Lagudah E, Appels R, McNeil D. The Nor-D3 locus of Triticum tauschii: natural variation and genetic linkage to markers in chromosome 5. Genome, 1991, 34(3): 387-395

22. Liu C, Yang Z J, Li G R, Zeng Z X, Zhang Y, Zhou J P, Liu Z H, Ren $Z$ L. Isolation of a new repetitive DNA sequence from Secale africanum enables targeting of Secale chromatin in wheat background. Euphytica, 2008, 159(1-2): 249-258 
23. Lv J, Lu Y, Niu Y, Whent M, Ramadan M F, Costa J, Yu L L. Effect of genotype, environment, and their interaction on phytochemical compositions and antioxidant properties of soft winter wheat flour. Food Chemistry, 2013, 138(1): 454-462

24. Konopka I, Czaplicki S, Rotkiewicz D. Differences in content and composition of free lipids and carotenoids in flour of spring and winter wheat cultivated in Poland. Food Chemistry, 2006, 95(2): 290-300
25. Moore J, Hao Z, Zhou K, Luther M, Costa J, Yu L L. Carotenoid, tocopherol, phenolic acid, and antioxidant properties of Marylandgrown soft wheat. Journal of Agricultural and Food Chemistry, 2005, 53(17): 6649-6657

26. Humphries J M, Graham R D, Mares D J. Application of reflectance colour measurement to the estimation of carotene and lutein content in wheat and triticale. Journal of Cereal Science, 2004, 40(2): 151159 